\title{
Proteomic Analysis of the Aging-related Proteins in Human Normal Colon Epithelial Tissue
}

\author{
Ming Li ${ }^{1,2, \#}$, Zhi-Qiang Xiao ${ }^{1, \#}$, Zhu-Chu Chen ${ }^{1,2, *}$, Jian-Ling $\mathrm{Li}^{1}$, Cui Li ${ }^{1}$, Peng-Fei Zhang and $\mathrm{Mao}^{1}-\mathrm{Yu} \mathrm{Li}^{1}$ \\ ${ }^{1}$ Key Laboratory of Cancer Proteomics of Chinese Ministry of Health, Xiangya Hospital, \\ Central South University, Changsha 410008, Hunan Province, China \\ ${ }^{2}$ Cancer Research Institute, Xiangya School of Medicine, Central South University, \\ Changsha 410078, Hunan Province, China
}

Received 21 June 2006, Accepted 12 September 2006

\begin{abstract}
In order to screen the aging related proteins in human normal colon epithelia, the comparative proteomics analysis was applied to get the two-dimensional electrophoresis (2DE) profiles with high resolution and reproducibility from normal colon epithelial tissues of young and aged people. Differential proteins between the colon epithelia of two age groups were found with PDQuest software. The thirty five differential protein-spots were identified by peptide mass fingerprint (PMF) based on matrix-assisted laser desorption/ ionization time-of-flight mass spectrometry (MALDI-TOFMS) and database searching. Among them there are sixteen proteins which are significantly up-regulated in the colonic mucosal epithelia of young people group, which include ATP synthase beta chain, electron transfer flavoprotein alpha-subunit, catalase, glutathione peroxidase 1 , annexin A2 and heat shock cognate $71 \mathrm{kDa}$ protein, etc.; There are nineteen proteins which are significantly up-regulated in the colonic mucosal epithelia of aged people group, which include far upstream element-binding protein 1 , nucleoside diphosphate kinase $B$, protein disulfide-isomerase precursor and VDAC-2, etc.. The identified differential proteins appear to be involved in metabolism, energy generation, chaperone, antioxidation, signal transduction, protein folding and apoptosis. The data will help to understand the molecular mechanisms of human colon epithelial aging.
\end{abstract}

Keywords: Aging, Colon epithelium, Differential expression protein, MALDI-MS Two-dimensional gel electrophoresis

\footnotetext{
\#These first two authors contributed equally to this work

*To whom correspondence should be addressed.

Tel: 86-731-4327239; Fax: 86-731-4327321

E-mail: tcbl@xysm.net
}

\section{Introduction}

The colon is an important human organ and its epithelium plays a central role in many physiological functions including digestion, absorption, secretion and defense etc.. Aging which involves a slow decline in the physiological activity of human colonic epithelium is also associated with many colonic disorders including colon cancers (Xiao et al., 1999). The incidence rate of colon cancer increases dramatically with ages, before 40 years old it is much lower and it reaches the peak in seventies (Fante et al., 1997). Explanations have been offered for the age-related increase in colon cancer incidence such as altered carcinogen metabolism (Nensey et al., 1995), the cumulative effects of long-term exposure to certain carcinogens (Birnbaum and Baird, 1979), cell hyperproliferation (Holt and Yeh, 1988), genetic alterations (Fearon, 1992) and altered gene methylation level (Issa et al., 1994). Although these studies revealed a part of mechanism of the susceptibility of aged colonic epithelium to carcinogenesis, it is far from being elucidated comprehensively and systematically.

Majority of researches about colonic epithelial aging process and the susceptibility of aged colonic epithelium to diseases focused on one or several genes (Xiao and Majumdar, 2001; Xiao et al., 2001) and stayed at the level of DNA or RNA, such as investigating aging-related changes in gene expression patterns in colonic epithelium using cDNA microarray analysis (Lee et al., 2001). Since it is proteins, which are the active agents in cells, that carry out nearly most of the vital activities and there is no strict linear relationship between the expression level of the mRNAs and that of the proteins (Gygi et al., 1999), global analysis of changes in protein expression in colonic epithelium during normal aging process is necessary for a better understanding colonic epithelial aging process and aging-related diseases including malignancy.

Proteomics, a new science which deals with total sets of proteins of different stage in a cell, an organ or an individal 
with proteomic technique, provides a high throughout method to study the complexity of life. Through proteomics analysis we can find out the physiological or pathological processrelated proteins and elucidate the important physiological and pathological phenomena. The emergence of proteomics also offers new tools for investigating the mechanisms of colonic epithelial aging and aging-related diseases.

The samples of this study are the human normal colon epithelium from different age groups. Firstly, high quality 2DE images of tissue proteins were prepared and then PDQuest software was used to analyze the 2-DE images to find the differentially expressed proteins by the comparison of the difference of protein profiles of human colon epithelium from different age group; secondly differentially expressed proteins were identified by the application of MALDI-TOF-MS technology and database searching. The results presented here will no doubt provide clues to elucidate the molecular mechanism of the colon epithelial aging and aging-related diseases.

\section{Materials and Methods}

Tissue samples and protein extraction. Human normal colonic epithelia were obtained from 30 healthy male volunteers aged 2565 years old at Xiangya Hospital, Central South University, Hunan, China. They were divided into two groups according to their ages: young (age 25-30, 15 volunteers) and old (age 60-65, 15 volunteers) group. Only the superficial layer of the colonic mucosa was collected under endoscope to ensure that the tissue samples consist mostly of epithelium. The tissues were immediately frozen in liquid nitrogen after excision and flushing out of blood with normal saline, and then stored at liquid nitrogen until use. Frozen epithelial tissue (about $30-40 \mathrm{mg}$ ) was homogenized in $400 \mu \mathrm{l}$ lysis buffer [7 mol/L urea, $2 \mathrm{~mol} / \mathrm{L}$ thiourea, $2 \%(\mathrm{v} / \mathrm{v}) \mathrm{NP}-40,1 \%$ (v/v) Triton $\mathrm{X}-100,100 \mathrm{mmol} / \mathrm{L}$ DTT, $5 \mathrm{mmol} / \mathrm{L}$ PMSF, 4\% CHAPS, 0.5 $\mathrm{mmol} / \mathrm{L}$ EDTA, $40 \mathrm{mmol} / \mathrm{L}$ Tris, $2 \%$ (v/v) pharmalyte, $1 \mathrm{mg} / \mathrm{ml}$ DNase I, and $0.25 \mathrm{mg} / \mathrm{ml}$ RNase A]. Crude lysates were shaken for $1 \mathrm{~h}$ on ice, followed by a $45 \mathrm{~min}$ centrifugation at $12,000 \mathrm{~g}$ at $4^{\circ} \mathrm{C}$. The supernatant was collected to a fresh tube and stored at $-80^{\circ} \mathrm{C}$ until use. The concentration of the total proteins was determined using 2D Quantification Kit (Amersham Biosciences).

Two-dimensional gel electrophoresis. 2-DE was performed as recommened by the manufacturer (Amersham Biosciences). The first dimension isoelectric focusing (IEF) electrophoresis was performed using IPG gel strip ( $\mathrm{pH}$ 3-10 NL, $24 \mathrm{~cm}$ ) on IPGphor (Amersham Biosciences). Samples containing $450 \mu \mathrm{g}$ proteins were diluted to $450 \mu \mathrm{l}$ with rehydration solution [ $8 \mathrm{~mol} / \mathrm{L}$ urea, $2 \%$ CHAPS, $20 \mathrm{mM}$ DTT, $0.5 \%(\mathrm{v} / \mathrm{v})$ pH3-10 IPG buffer, trace bromophenol blue], and applied to IPG strips by $14 \mathrm{~h}$ rehydration at $30 \mathrm{~V}$. Proteins were focused successively for $1 \mathrm{~h}$ at $500 \mathrm{~V}, 1 \mathrm{~h}$ at $1,000 \mathrm{~V}$ and $8.5 \mathrm{~h}$ at $8,000 \mathrm{~V}$ to give a total of $69,920 \mathrm{vhrs}$ on an IPGphor. Focused IPG gel strips were equilibrated for $15 \mathrm{~min}$ in a solution $(6 \mathrm{~mol} / \mathrm{L}$ urea, $2 \% \mathrm{SDS}, 30 \%$ glycerol, $50 \mathrm{mmol} / \mathrm{L}$ TrisHCI, pH 8.8 and 1\% DTT), and then for an additional $15 \mathrm{~min}$ in the same solution except that DTT was replaced by $2.5 \%$ iodoacetamide. After equilibration, the second dimensional separation was performed on $12.5 \% \mathrm{~T}, 2.5 \% \mathrm{C}$ sodium dodecy 1 sulfate polyacrylamide gels with the Ettan DALT system (Amersham Biosciences) according to the method described by Gorg (Gorg et al., 2000). After SDSPAGE, gels were stained with silver nitrate according to the protocol of Plusone sliver staining kit (Amersham Biosciences). Molecular masses were determined by running standard protein markers covering the range of $10-100 \mathrm{kDa}$ and $\mathrm{pI}$ values were calculated as given by the supplier of the immobilized $\mathrm{pH}$ gradient strips (Amersham Biosciences). Each experiment was performed in triplicate.

Image analysis. 2-DE maps were obtained by scanning the gels using the Imagescanner. Analysis of the gels was accomplished using the PDQuest analysis software including background subtraction, spots detection, volume normalization and the establishment of a reference gel. Average gels were matched to the reference gel, a virtual gel which containing all spots detected on any gel, and the average gels derived from young and old groups were compared. Intensity of each spot was quantified by calculation of spot volume after normalization of the image using the total spot volume normalization method multiplied by the total area of all the spots. Statistical analysis was carried out with SPSS for Windows 10.01 and Excel. Average gels from fifteen independent experiment were compared to each other and spots having statistic difference $(p<0.05)$ in intensity were selected for further identification by MALDI-TOF-MS.

In-gel digestion. Differently expressed protein spots between the two groups were excised manually from stained 2-DE gels, transferred to a $1.5 \mathrm{ml}$ Eppendorf tube, and rinsed three times with ultrapure water. The gel-spots were destained in destaining solution consisting of $100 \mathrm{mmol} / \mathrm{L} \mathrm{Na}_{2} \mathrm{~S}_{2} \mathrm{O}_{3}$ and $30 \mathrm{mmol} / \mathrm{L} \mathrm{K}_{3} \mathrm{Fe}(\mathrm{CN})_{6}(\mathrm{v} / \mathrm{v}$, $1: 1)$. After dehydrated with Acetonitrile $(\mathrm{ACN})$, the gel pieces were dried thoroughly in a vacuum centrifuge for $50 \mathrm{~min}$. The dried gel pieces were reconstituted with $5 \mu \mathrm{l}$ of $50 \mathrm{mmol} / \mathrm{L} \mathrm{NH}_{4} \mathrm{HCO}_{3}$ containing $100 \mu \mathrm{g} / \mathrm{mL}$ trypsin (Promega, Madison, WI, USA) and the proteins were digested for 16 hours at $37^{\circ} \mathrm{C}$. Peptides extraction was performed with $30 \mu \mathrm{l}$ solution consisting of $50 \% \mathrm{ACN}$ and $2.5 \%$ trifluoroacetic acid (TFA) and condensed in vacuum centrifuge to no more than $5 \mu$ of terminal volume.

Protein identification using MALDI-TOF-MS and database searching. Extracted peptide samples were prepared using $\alpha$ cyano-4-hydroxycinnamic acid as the MALDI-TOF -MS matrix. The matrix solution was saturated in $50 \%$ ACN and $0.1 \%$ TFA. The peptide solution $(0.5 \mu \mathrm{l})$ was applied first to the sample plate target, then matrix solution $(0.5 \mu \mathrm{l})$ was added on the plate target mixed with the peptide solution. After the samples were airevaporated, MALDI-TOF-MS was performed on a Voyage-DE STR MALDI-TOF Mass Spectrometer (ABI). The parameters of MALDI-TOF were set up as follows: accelerating voltage $20 \mathrm{kV}$; grid voltage $64.5 \%$; delay $100 \mathrm{~ns}$; the number of laser shots 50 and the acquisition mass range $900 \mathrm{Da}-3,500 \mathrm{Da}$. The spectra were internally calibrated using two peptides arising from trypsin autoproteolysis $\left([\mathrm{M}+\mathrm{H}]^{+}\right.$842.5100; $[\mathrm{M}+\mathrm{H}]^{+}$2211.1046). Peptide mass fingerprintings (PMF) obtained in the positive ion reflector mode in Monoisotopic peptide masses were searched in the SWISS-PROT database using Mascot software (http://www. 
matrixscience.com) with the following parameters: taxonomy was selected as homo sapiens (Human); the mass tolerance was \pm 50 ppm; The missed cleavage sites were allowed up to 1; the fixed modification was selected as carbamidomethylation (cysteine); the variable modification was selected as oxidation (methionine). The probability scores calculated by software were used as criterion for correct identification.

\section{Results}

2-DE pattern and differential analysis of human colonic epithelial tissues from young and old people. Human colonic epithelial proteins from 15 young healthy male volunteers (age 25-30 years) and 15 old healthy male volunteers (age 6065 years) were respectively solubilized in the IEF-compatible lysis buffer, and separated on IPGstrips and SDS-PAGE. Following staining with silver nitrate, the well-resolved and reproducible 2-D gel maps of colonic epithelial tissues from young and old people were obtained, which are displayed in Fig. 1A and 1B. Using PDQuest 2-DE gels analysis software, approximately 1462 well-stained, clearly-delineated protein spots were detected, and most spots were distributed in range from $\mathrm{pH} 5$ to $\mathrm{pH}$ 8. Forty-seven spots which showed remarkable change $(p<0.05)$ between old and young groups had been observed, of which 26 spots were up-regulated and 21 spots down-regulated. These differentially expressed protein spots are illustrated with arrows in Fig. 1A and 1B. Close-up of the region of the gels showing differentially expressed protein between human colonic epithelial tissues from young and old people was shown in Fig. 2.

Proteins identified by MALDI-TOF-MS. Differentially expressed protein spots were excised from the 2-DE gel, and analyzed for protein identification by MALDI-TOF-MS. With MALDI-TOF-MS analysis 42 peptide mass finger prints (PMF) were successfully obtained. All PMFs were searched with Mascot software in SWISS-PROT database to identify the protein spots. The result had high confidence if the protein was ranked as the best hit with a significant score and high sequence coverage. Finally, we identified 35 proteins in those spots, which are shown in Table 1. A representative PMF map and database query result of protein spot 27 were shown in Fig. 3, and the query result showed that protein spot 27 was protein disulfide-isomerase precursor.

Subcellular localization and functional groups of the identified proteins. The 35 identified proteins of colonic epithelium have been classified in terms of their subcellular localization and biological function by information from SWISS-PROT database. Subcellular location of the detected proteins is graphically illustrated in Fig. 4A. The majority of identified proteins fall in the cytoplasm $(17 \%)$, mitochondrion (20\%), several compartments $(23 \%)$, ER (11\%) and nuclear $(9 \%)$, with an approximate $11 \%$ determined to be of unknown
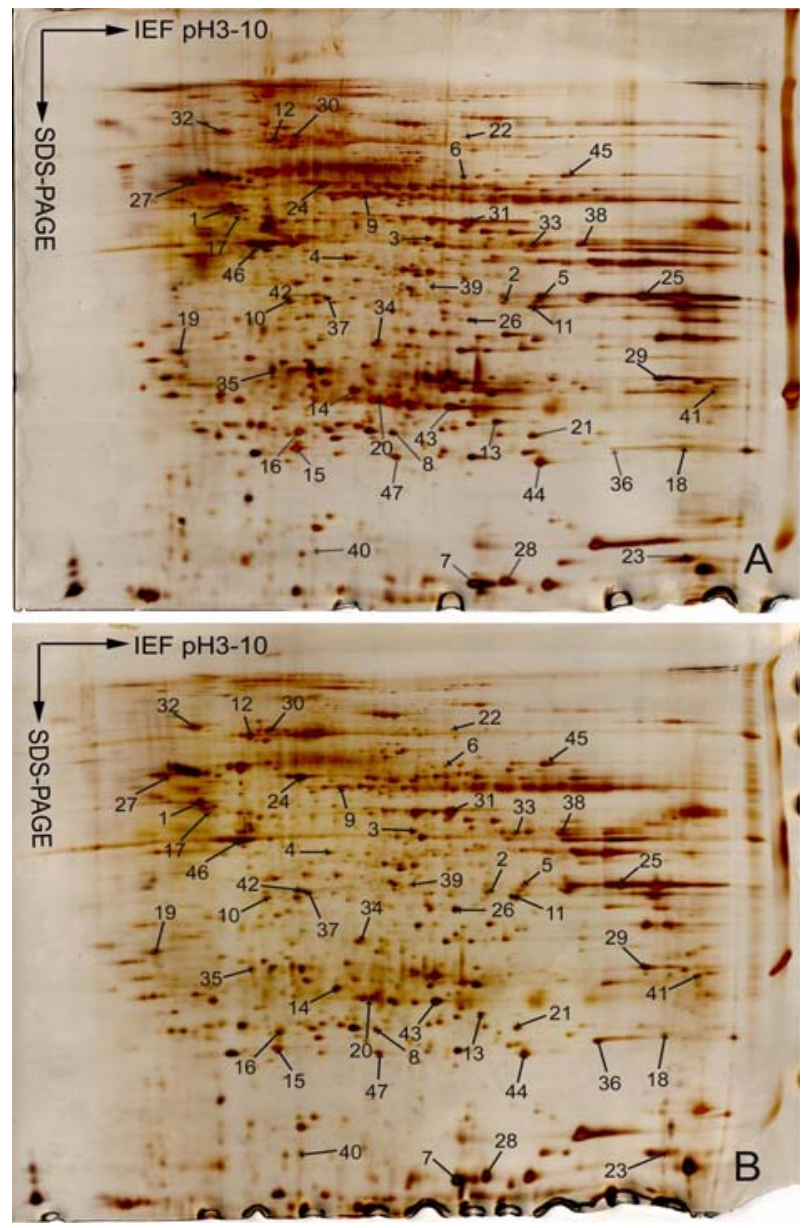

Fig. 1. (A) Two-dimensional electrophoresis map of $450 \mu \mathrm{g}$ proteins extracted from the normal colon epithelial tissue of young people. (B) Two-dimensional electrophoresis map of $450 \mu \mathrm{g}$ proteins extracted from the normal colon epithelial tissue of old people.

location. Only $6 \%$ cell membrane associated proteins, $3 \%$ peroxisome protein were identified.

Functional classification of the identified proteins is graphically illustrated in Fig. 4B. The identified proteins could be divided into several main groups based on their functions: proteins related to antioxidation (26\%) and signal transduction $(17 \%)$, protein involved in apoptosis $(9 \%)$, chaperone $(11 \%)$, protein folding $(9 \%)$. Other categories involved intermediary metabolism $(9 \%)$, transcription \& translation $(9 \%)$, energy generation $(5 \%)$ and structural proteins $(5 \%)$.

\section{Discussion}

The aging of the human colon epithelia is a complex process involving various events and steps. Many studies have been done at gene level to elucidate the molecular mechanism of this process, while little is known about the effect of aging on whole protein expression in colon mucosal epithelium. In the 


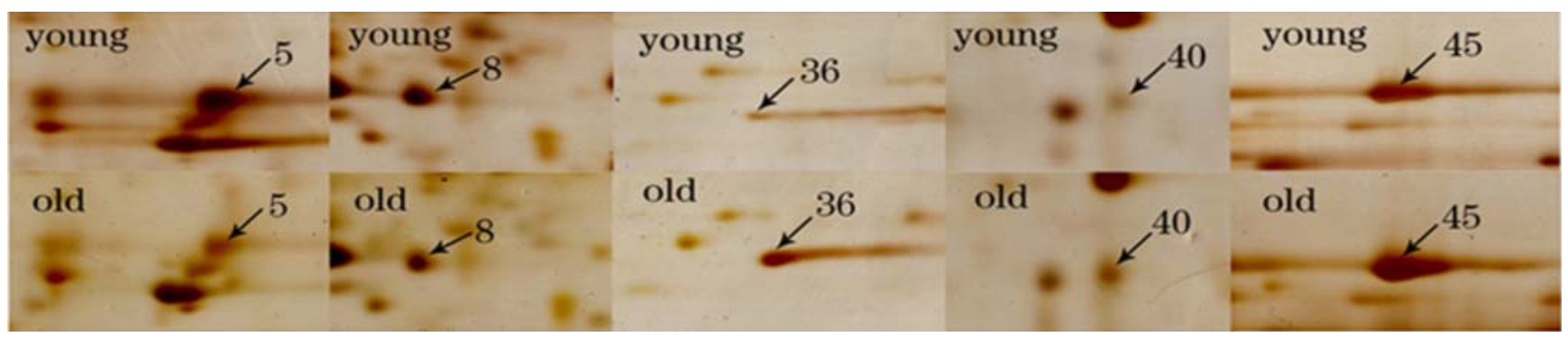

Fig. 2. Close-up image of partial differential expression of protein spots $(5,8,36,40,45)$ between young people group and old people group. The protein expression levels of spots $(5,8)$ were up-regulated in young people group; the protein expression levels of spots $(36$, $40,45)$ were up-regulated in old people group.

present study, the comparative proteomic analysis of normal colon epithelial tissues between young and old people was performed. 35 aging related proteins were identified whose functions appear to be involved in metabolism, energy generation, chaperone, antioxidation, signal transduction, protein folding and apoptosis.

Mitochondrion undertakes several important functions such as producing ATP, regulating calcium's dynamic balance and initiating apoptosis signals etc. It is believed that mitochondrion plays an important role in the aging process as well as aging associated diseases. According to free radical theory, first proposed by Harman (Harman, 1956), reactive oxygen species (ROS) are capable of damaging biomolecules, including proteins, sugars, fatty acid and nucleic acids, leading to the dysfunction or aging of cells and organs. However, the major source of free radicals and oxidants is the mitochondrial generation of ATP energy using oxygen. Therefore mitochondrion is also the primary attacking target of ROS. This partly explained why mitochondrial proteins account for a major percent in the identified aging related colon epithelial proteins.

Among the identified aging related mitochondrial proteins, ATP synthase beta chain, electron transfer flavoprotein alphasubunit directly participate in the process of energy production; Elongation factor Tu promotes the translocation of amino acid during protein synthesis; Thiosulfate sulfurtransferase forms iron-sulfur complexes, detoxicates cyanide or modifies sulfurcontaining enzyme. Decrease of their expression levels in aged colonic epithelium implies the decline of mitochondrial function with aging. There are evidences support that ageassociated accumulation of mitochondrial deficits is likely to be a major contributor to cellular, tissue, organismal aging (Shigenaga et al., 1994). Our data are also in accord with McCarroll's study. They found that the expression levels of many genes which participated in ATP synthesis or mitochondrial respiration decreased by about 2 times in aged Caenorhabditis elegans and Drosophila melanogaster (McCarroll et al., 2004).

In cells there also exist enzymes such as Catalase (Beckman and Ames, 1998), peroxiredoxin (Fujii and Ikeda, 2002) and Glutathione peroxidase 1 (Beckman and Ames, 1998) which are capable of scavenging ROS and protecting them from oxidative damage. The decrease of expression level of the above mentioned anti-peroxidases and proteins in the aged colonic epithelium in the present study suggests the decline of antioxidant activity plays an important key in the aging of human colonic epithelium.

During the aging period of cell, a great amount of extracellular calcium flows into cytoplasmic matrix due to the membrane leakage. As a result of the binding of $\mathrm{Ca}^{2+}$ and calmodulin, a series of biological effects occur. For instance, the activation of phospholipase by $\mathrm{Ca}-\mathrm{CaM}$ will cause the separation of unsaturated fatty acid which will form hydroxyl peroxide in the presence of lipoxygenase. The hydroxyl peroxide and its self-degraded products (such as malondialdehyde and ethane) can result in the breakdown and leakage of membrane. And subsequently more and more $\mathrm{Ca}^{2+}$ flows into cell, which brings a cascade reaction. As a result, the phospholipid is degraded and cell membrane is broken down. However Annexin A2 can inhibit such pathway by inhibiting phospholipase A2 (Huang et al., 1986), which results in the inhibition of aging. This fact just interprets the phenomena that Annexin A2 is highly expressed in colon epithelial tissues of young people.

Heat shock cognate $71 \mathrm{KD}$ protein (HSC 70) not only can inhibit the apoptosis mediated by JNK (Mosser et al., 1997), but also can block the pathway of cell apoptosis by inhibiting of the activities of Caspase 3 and Caspase 9 respectively (Jaattela et al., 1998), which results in the inhibition of aging process. Heat shock protein 27, another member of HSP family, playing as a chaperone in vivo, also can prevent the cells from aging by inhibition of the programmed cell death after its combination with the signal molecules of apoptosis signaling pathway (Garrido et al., 1999). In this study, the high expressions of Heat shock cognate $71 \mathrm{kDa}$ protein (HSC 70) and HSP 27 in colon epithelial tissues of young people indicate these two proteins possess the activity of anti-aging.

$C-m y c$ gene which is associated with many apoptosis related proteins is a proto-oncogene with multiple functions. The continuous expression of $C-m y c$ gene will accelerate the development of apoptosis (Askew et al., 1991). Far upstream element-binding protein 1, a single-stranded DNA binding protein of eukaryote, can activate the transcription of $C$-myc gene by combining with the single-stranded DNA of far 


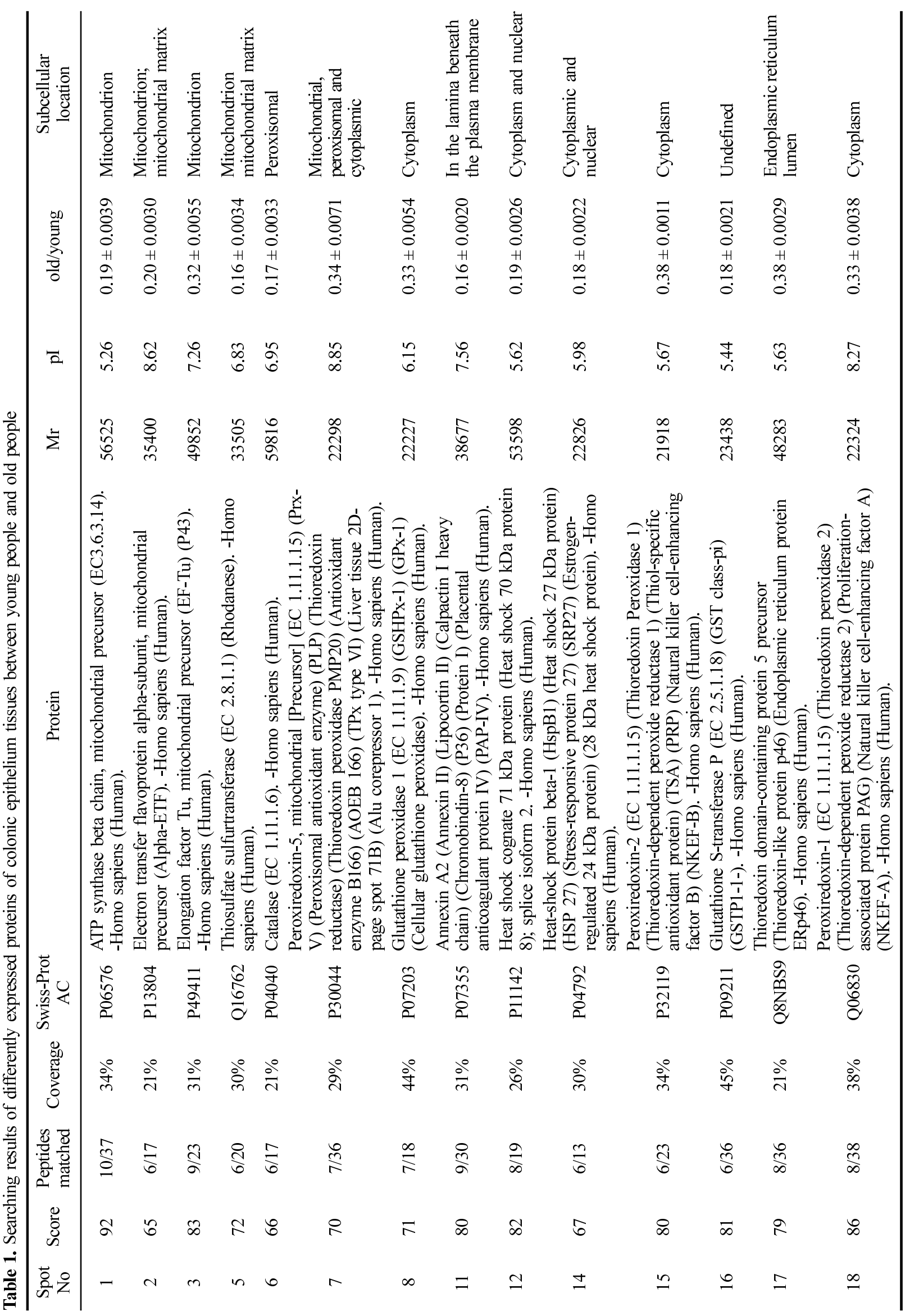




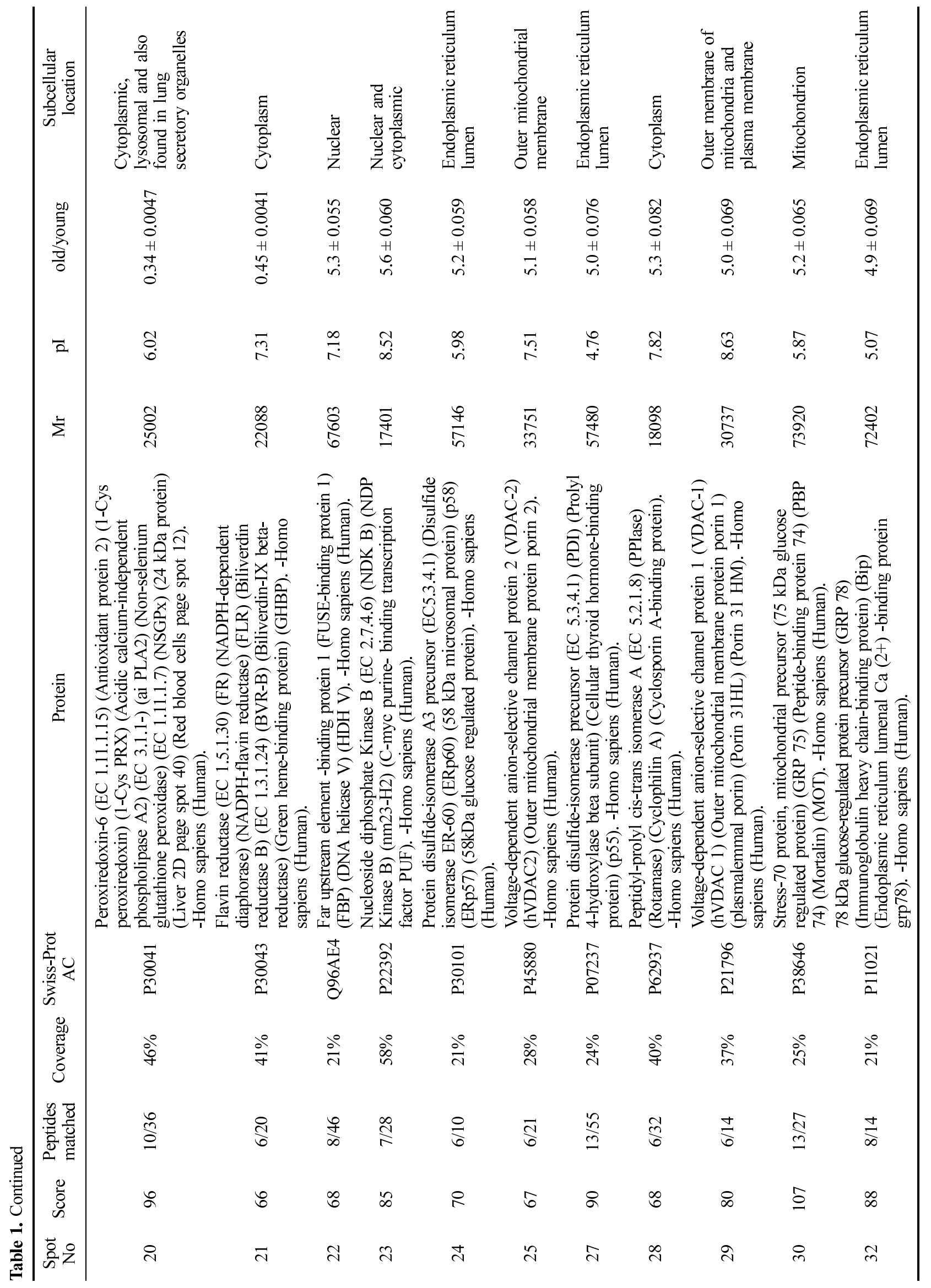




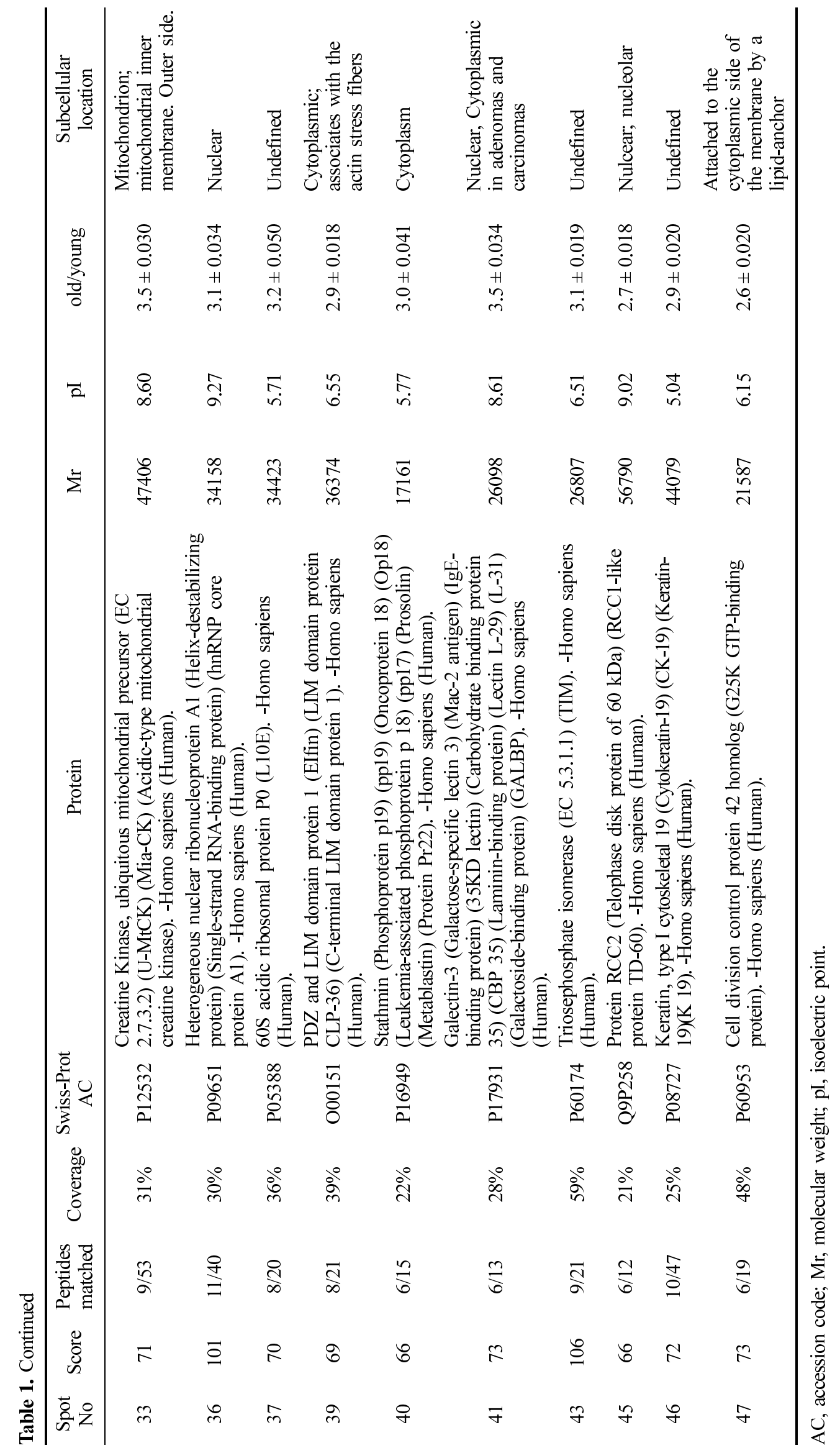


(A) Voyager Spec \#1[BP $=1834.8,5626]$

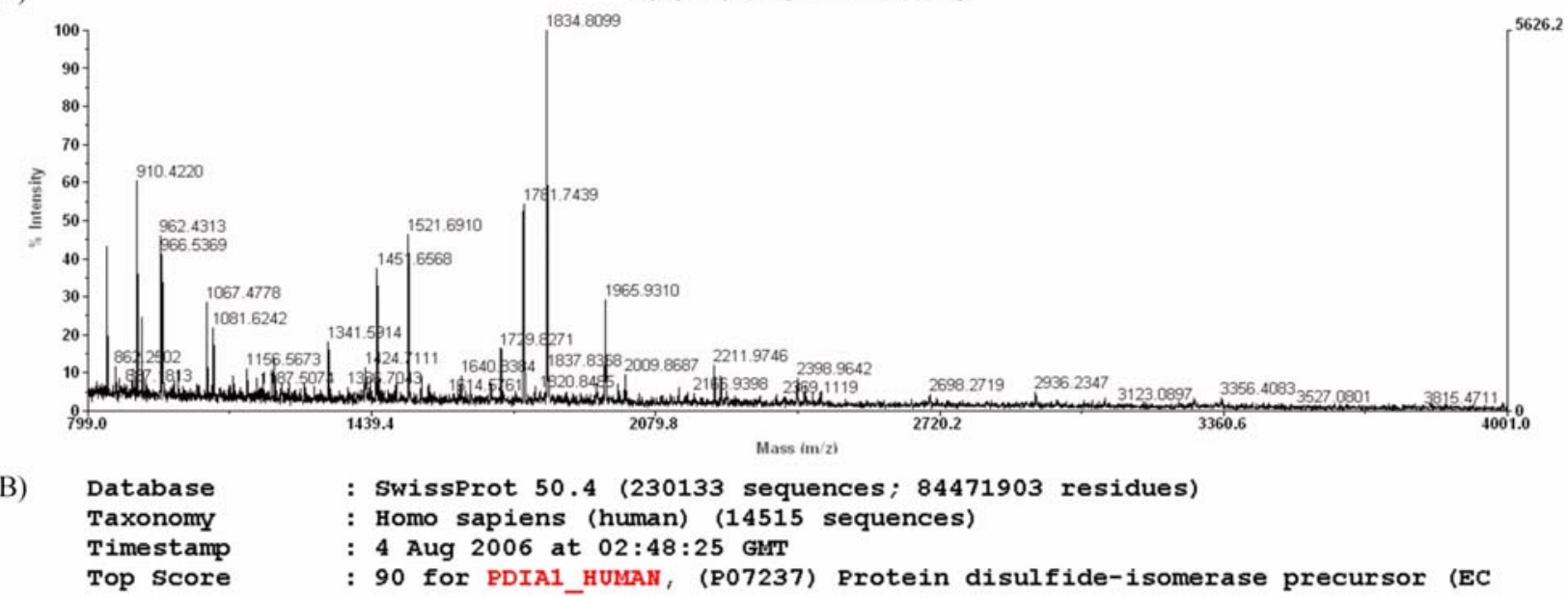

Probability Based Mowse Score

Protein score is $-10 * \log (\mathrm{P})$, where $\mathrm{P}$ is the probability that the observed match is a random event. Protein scores greater than 54 are significant $(\mathrm{p}<0.05)$.

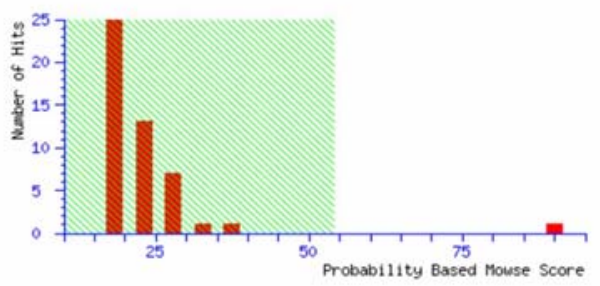

(C) Fixed modifications: Carbamidomethyl (C)

Variable modifications: oxidation (M)

Cleavage by Trypsin: cuts C-term side of $\mathrm{KR}$ unless next residue is $\mathrm{P}$

Number of mass values searched: $\mathbf{5 5}$

Number of mass values matched: 13

Sequence Coverage: $24 \%$

Matched peptides shown in Bold Red

1 MLRRALLCLA VAALVRADAP EEEDHVLVLR KSNFAEALAA HKYLLVEFYA

51 PWCGHCKALA PEYAKAAGKL KAEGSEIRLA KVDATEESDL AQQYGVRGYP

101 TIKFFRNGDT ASPKEYTAGR EADDIVNWLK KRTGPAATTL PDGAAAESLV

151 ESSEVAVIGF FKDVESDSAK OFLQAAEAID DIPFGITSNS DVFSKYQIDK

201 DGVVLFKKFD EGRNNFEGEV TKENLLDFIK HNQLPLVIEF TEQTAPKIFG

251 GEIKTHILLF LPKSVSDYDG KLSNFKTAAE SFKGKILFIF IDSDHTDNOR

301 ILEFFGLKKE ECPAVRLITL EEEMTKYKPE SEELTAERIT EFCHRFLEGK

351 IKPHLMSQEL PEDWDKQPVK VLVGKNFEDV AFDEKKNVFV EFYAPWCGHC

401 KQLAPIWDKL GETYKDHENI VIAKMDSTAN EVEAVKVHSF PTLKFFPASA

451 DRTVIDYNGE RTLDGFKKFL ESGGODGAGD DDDLEDLEEA EEPDMEEDDD

501 QKAVKDEL

(D)
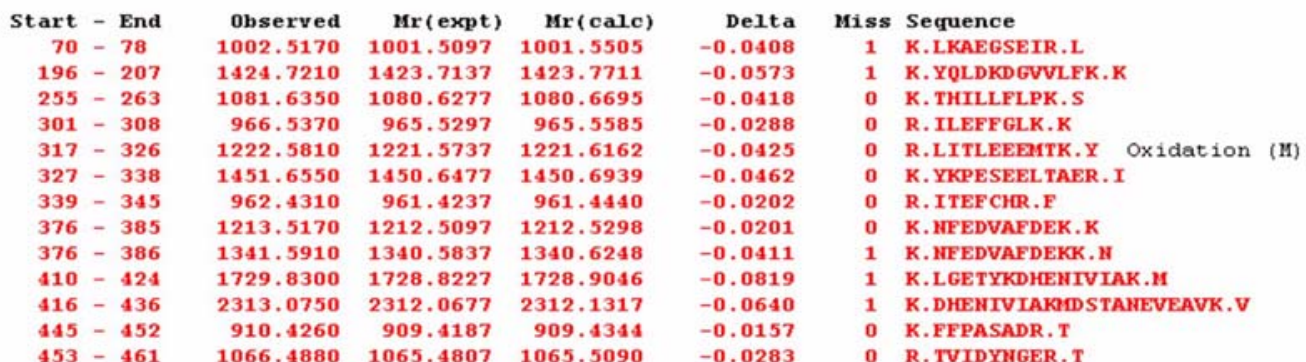

Fig. 3. A representative MALDI-TOF mass spectrometry map and database query result (spot27). (A) Monoisotopic peaks of MALDITOF MS map. (B) Database query result and scores. (C) Protein sequence and sequence coverage. (D) Matched peptide fragment and error between experimental mass and theoretical mass. 

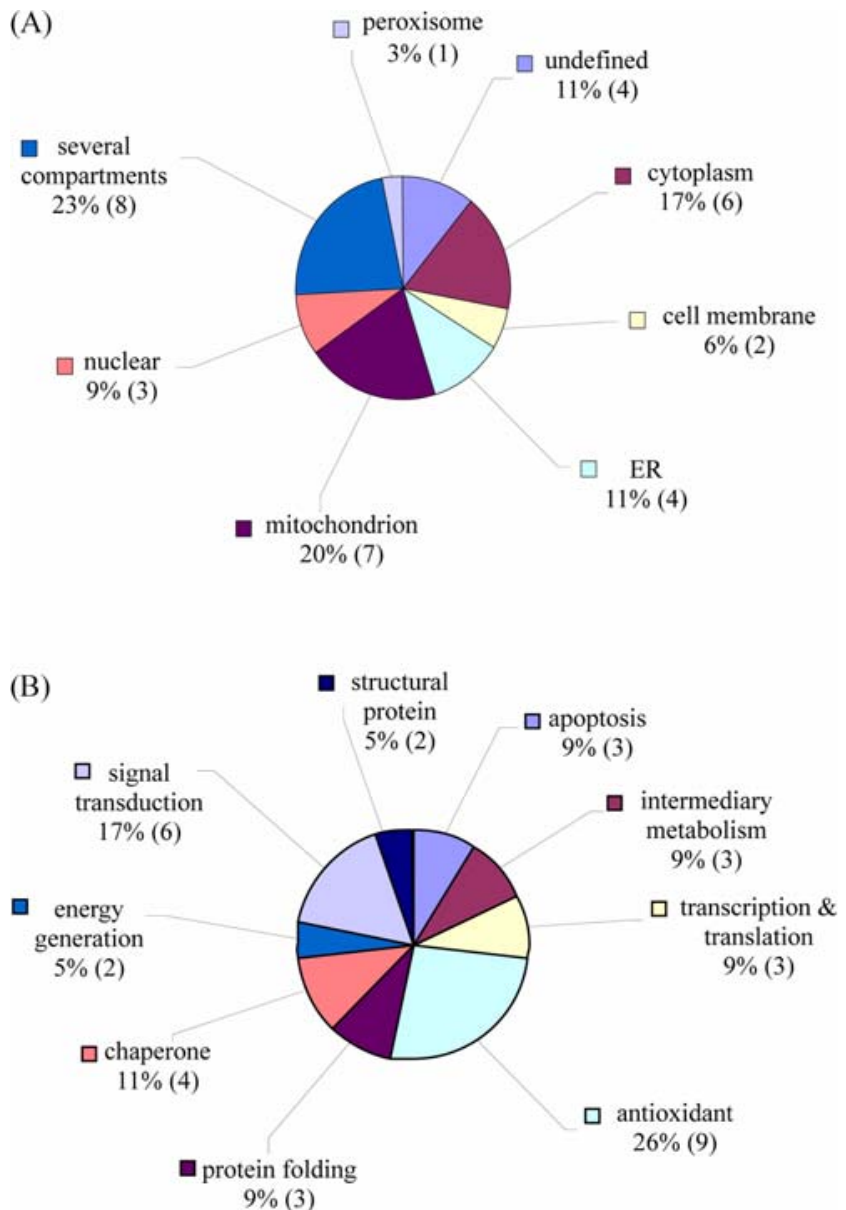

Fig. 4. Pie charts representing (A) the distribution of the 35 identified proteins in human colonic epithelium according to their subcellular localization and (B) the distribution of the 35 identified proteins in human colonic epithelium according to their biological function. Assignments were made on the basis of information provided from the SWISS-PROT database. The number in the brackets represents the number of identified protein.

upstream element of C-myc gene promoter (He et al., 2000). Nucleoside diphosphate kinase B (nm23-H2) can promote the apoptosis as the transcription factor of C-myc gene (Postel et al., 1993). In this thesis, the high expressions of Far upstream element-binding protein 1 and nucleoside diphosphate kinase B (nm23-H2) in colon epithelial tissue of old people suggest that these two proteins could promote the development of aging.

Experiments show nucleoskeleton protein is a disulfide bond rich protein. However, in aging cell the much abundant disulfide bonds of nucleoskeleton protein play a major role in the pyknosis of chromatin, because they can cause the further pyknosis of chromatin in aging cell. In this study, we find protein disulfide-isomerase precursor which catalyzes the formation, isomerization, and reduction of disulfide bond (Freedman et al., 1989) is up-regulatedly expressed in colon epithelial tissues of old people. So protein disulfide-isomerase precursor is considered to be one of the proteins associated with promotion of aging.

In this study, through comparative proteomics analysis of colonic epithelium between young and old men, 35 aging related proteins were identified by $2-\mathrm{DE}$ in combination with MALDI-TOF-MS, the expressional level changes of which indicate that injury of mitochondrial function, decline of antioxidant capability and increase of apoptosis are important reasons for the aging of human colonic epithelium. The results present here will no doubt provide clues to elucidate the molecular mechanism of the colon epithelial aging and agingrelated diseases.

Acknowledgments This work was supported by grants from the Outstanding Scholars of New Era from Ministry of Education of China (2002-48), and the National Natural Science Foundation of China (30240056, 30370642).

\section{References}

Askew, D. S., Ashmun, R. A., Simmons, B. C. and Cleveland, J. L. (1991) Constitutive c-Myc expression in an IL-3-dependent myeloid cell line suppresses cell cycle arrest and accelerates apoptosis. Oncogene 6, 1915-1922.

Beckman, K. B. and Ames, B. N. (1998) The free radical theory of aging matures. Physiol. Rev. 78, 547-581.

Birnbaum, L. S. and Baird, M. B. (1979) Senescent changes in rodent hepatic epoxide metabolism. Chem. Biol. Interact. 26, 245-256.

Fante, R., Benatti, P., di Gregoroio, C., De Pietri, S., Pedroni, M. and Tamassia, M. G. (1997) Colorectal carcinoma in different age groups: a population-based investigation. Am. J. Gastroenterol. 92, 1505-1509.

Fearon, E. R. (1992) Genetic alterations underlying colorectal tumorigenesis. Cancer Surv. 12, 119-136.

Freedman, R. B., Bulleid, N. J., Hawkins, H. C. and Paver, J. L. (1989) Role of protein disulphide-isomerase in the expression of native protein. Biochem. Soc. Symp. 55, 167-192.

Fujii, J. and Ikeda, Y. (2002) Advances in our understanding of peroxiredoxin, a multifunctional, mammalian redox protein. Redox. Rep. 7, 123-130.

Garrido, C., Bruey, J. M., Fromentin, A., Hammann, A., Arrigo, A. P. and Solary, E. (1999) HSP27 inhibits cytochrome cdependent activation of procaspase 9. FASEB J. 13, 2061-2070.

Gorg, A., Obermaier, C., Boguth, G., Harder, A., Scheibe, B., Wildgruber, R. and Weiss, W. (2000) The current state of twodimensional electrophoresis with immobilized $\mathrm{pH}$ gradients. Electrophoresis 21, 1037-1053.

Gygi, S. P., Rochon, Y., Franza, B. R. and Aebersold, R. (1999) Correlation between protein and mRNA abundance in yeast. Mol. Cell Biol. 19, 1720-1730.

Harman, D. (1956) Aging: a theory based on free radical and radiation chemistry. J. Gerontol. 11, 298-300.

He, L. S., Weber, A. and Levens, D. (2000) Nuclear targeting determinants of the far upstream element binding protein, a cmyc transcription factor. Nucleic Acids Res. 28, 4558-4565. 
Holt, P. R. and Yeh, K. Y. (1988) Colonic proliferation is increased in senescent rats. Gastroenterology 95, 1556-1563.

Huang, K. S., Wallner, B. P., Mattaliano, R. J., Tizard, R., Burne, C., Frey, A., Hession, C., McGray, P., Sinclair, L. K. and Chow, E. P. (1986) Two human $35 \mathrm{Kd}$ inhibitors of phospholipase A2 are related to substrates of pp60v-Src and of the epidermal growth factor receptor/Kinaes. Cell 46, 191-199.

Issa, J. P., Ottaviano, Y. L., Celano, P., Hamilton, S. R., Davidson, N. E. and Baylin, S. B. (1994) Methylation of the oestrogen receptor $\mathrm{CpG}$ island links ageing and neoplasia in human colon. Nat. Genet. 7, 536-540.

Jaattela, M., Wissing, D., Kokholm, K., Kallunki, T. and Egeblad, M. (1998) Hsp70 exerts its anti-apoptotic function downstream of caspase-3-like proteases. EMBO J. 17, 6124-6134.

Lee, H. M., Greeley, G. H. Jr. and Englander, E. W. (2001) Ageassociated changes in gene expression patterns in the duodenum and colon of rats. Mech. Ageing Dev. 122, 355-371.

McCarroll, S. A., Murphy, C. T., Zou, S., Pletcher, S. D., Chin, C. S., Jan, Y. N., Kenyon, C., Bargmann, C. I. and Li, H. (2004) Comparing genomic expression patterns across species identifies shared transcriptional profile in aging. Nat. Genet. 36, 197-204.

Mosser, D. D., Caron, A. W., Bourget, L., Denis-Larose, C. and Massie, B. (1997) Role of the human heat shock protein hsp70 in protection against stress-induced apoptosis. Mol. Cell. Biol.
17, 5317-5327.

Nensey, Y. M., Arlow, F. L. and Majumdar, A. P. (1995) Aging. Increased responsiveness of colorectal mucosa to carcinogen stimulation and protective role of folic acid. Dig. Dis. Sci. 40, 396-401.

Postel, E. H., Berberich, S. J., Flint, S. J. and Ferrone, C. A. (1993) Human c-myc transcription factor PuF identified as $\mathrm{nm} 23-\mathrm{H}_{2}$ nucleoside diphosphate kinase, a candidate suppressor of tumor metastasis. Science 261, 478-480.

Shigenaga, M. K., Hagen, T. M. and Ames, B. N. (1994) Oxidative damage and mitochondrial decay in aging. Proc. Natl. Acad. Sci. USA 91, 10771-10778.

Xiao, Z Q., and Majumdar, A. P. (2001) Increased in vitro activation of EGFR by membrane-bound TGF- alpha from gastric and colonic mucosa of aged rats. Am. J. Physiol. Gastrointest. Liver Physiol. 281, 111-116.

Xiao, Z. Q., Moragoda, L., Jaszewski, R., Hatfield, J. A., Fligiel, S. E. and Majumdar, A. P. N. (2001) Aging is associated with increased proliferation and decreased apoptosis in the colonic mucosa. Mech. Ageing Dev. 122, 1849-1864.

Xiao, Z. Q., Yu,Y. J., Khan, A., Jaszewski, R., Ehrinpreis, M. N. and Majumdar, A. P. N. (1999) Induction of G(1) checkpoint in the gastric mucosa of aged rats. Am. J. Physiol. 277, G929934. 